\title{
Role of ACE inhibitors in hypertension with left ventricular hypertrophy
}

\section{Departments of Medicine and Cardiology, Hospital. Christchurch, New Zealand A M Richards M G Nicholls I G Crozier \\ Correspondence to: Dr A M Richards, Cardio-Endocrinology, 3rd Floor, Princess Margaret Hospital, Cashmere Road,} Christchurch, New Zealand.

\author{
A Mark Richards, M Gary Nicholls, Ian G Crozier
}

Left ventricular hypertrophy in hypertension is an independent predictor for sudden death, ventricular arrhythmias, myocardial ischaemia, coronary heart disease, and heart failure..$^{1-9}$ These relations have proved true whether the hypertrophy is detected by electrocardiography or by the much more sensitive technique of echocardiography. It seems logical that regression of left ventricular hypertrophy would be beneficial, but, as yet, few clinical data support this contention beyond a limited experience from the Framingham study. Antihypertensive treatments might differ in their ability to promote regression of left ventricular hypertrophy independently of their blood pressure lowering effect. There is a powerful theoretical basis suggesting that inhibition of angiotensin converting enzyme (ACE), with consequent reduction in plasma and tissue concentrations of angiotensin II, may be superior in promoting regression of left ventricular hypertrophy. Studies in animal models of hypertension and meta-analyses of trials of drug treatment in human hypertension are not entirely concordant, but overall they support a major role for ACE inhibitors in reducing left ventricular hypertrophy.

\section{Left ventricular hypertrophy as risk factor}

The two widely used techniques for detecting left ventricular hypertrophy are electrocardiography and echocardiography. Echocardiography is by far the more sensitive, detecting hypertrophy in $14 \%$ and $18 \%$ of men and women respectively in the subjects of the Framingham heart study. By contrast, electrocardiographic features of left ventricular hypertrophy were present in only $2.9 \%$ of men and $1.5 \%$ of women in this population. ${ }^{10}$ Most studies using echocardiographic criteria for left ventricular hypertrophy apply the conventions of the American Society of Echocardiography. These define abnormally increased left ventricular mass as the population mean plus 2 SD. Echocardiography has provided a noninvasive means of estimating left ventricular mass with a close correlation to values at necropsy. ${ }^{11-14}$ In uncomplicated essential hypertension left ventricular mass on echocardiography satisfied criteria for hypertrophy (over $125 \mathrm{~g} / \mathrm{m}^{2}$ ) in $27 \%$ of patients. ${ }^{15}$ In the same study cardiovascular events occurred in a higher proportion of patients with left ventricular hypertrophy than in those without $(26 \% v 12 \%, \mathrm{P}<0.01)$. Cardiovascular death was 28 times more common in the group with left ventricular hypertrophy $(14 \% v 0.5 \%$, $P<0.001)$, all cause mortality being eight times more common $(16 \%$ v $2 \%, \mathrm{P}<0.01)$. Patients with normal left ventricular geometry suffered no cardiac death and only $11 \%$ suffered a morbid event in contrast with those with concentric hypertrophy, who had a mortality of $21 \%$ and a morbidity of $31 \%$. In a larger population of more than 3000 people over 40 who were free of overt clinical cardiovascular disease and were followed up for four years, 208 cardiovascular end organ events occurred, including 37 cardiovascular deaths and 124 deaths from all causes. ${ }^{9}$ The relative risk of cardiovascular death was significantly increased for every $50 \mathrm{~g}$. increment in left ventricular mass (relative risk 1.73 for men and $2 \cdot 12$ for women). For all causes of death the corresponding relative risks were 1.49 in men and 2.01 in women. In a multivariate analysis the adverse prognostic significance of increased left ventricular mass was independent of age, diastolic blood pressure, pulse pressure, antihypertensive treatment, smoking, presence or absence of diabetes, presence or absence of obesity, lipid profile, and electrocardiographic evidence of left ventricular hypertrophy.

Recent studies using electrocardiographic criteria for detecting left ventricular hypertrophy confirm earlier indications that electrocardiographic hypertrophy is an independent indicator of both cardiovascular and all cause mortality. In a population of nearly 5000 patients undergoing coronary angiography over 13 years electrocardiographic evidence of left ventricular hypertrophy was present in $5 \cdot 2 \% .{ }^{16}$ Five year survival in this group was significantly less than in those without left ventricular hypertrophy $(81.9 \%$ v $90.2 \%$, $\mathbf{P}<0.001)$. This effect of hypertrophy was independent of coronary artery disease in that even in the presence of normal coronary angiograms, electrocardiographic left ventricular hypertrophy was associated with a reduced five year survival $(81.0 \% \vee 87 \cdot 7 \%$, $\mathrm{P}<0.01)$. Dunn et al analysed data from the Glasgow blood pressure clinic from nearly 4000 patients over a mean follow up period of more than six years and found that left ventricular hypertrophy was present by electrocardiographic criteria in $34.5 \%$ of men and $21.5 \%$ of women. ${ }^{17}$ All cause mortality in this population was 27.6 per 1000 patient years for men with a normal electrocardiogram compared with 43.2 per 1000 patient years in those with left ventricular hypertrophy seen electrocardiographically. In addition, those who also had "strain" in addition to other criteria for left ventricular hypertrophy on electrocardiography had a further increase in mortality to 56.9 per 1000 patient years. This 
association of electrocardiographic left ventricular hypertrophy with increased mortality was independent of age, blood pressure, and smoking.

The mechanism linking left ventricular hypertrophy with increased morbidity and mortality is uncertain. Possibilities include a mismatch of blood supply to tissue mass, leading to comparatively ischaemic subendocardial tissue. Basal myocardial oxygen demand may be increased because of increased wall mass and some increase in wall stress. There may be increased susceptibility to ventricular arrhythmia, which may be related to an increased component of fibrous tissue within the myocardium. Coronary reserve is reduced, leading to a lowered threshold for induction of ischaemia in the presence of stressors such as exercise and short term falls or rises in blood pressure.

Thus, left ventricular hypertrophy is an undeniably undesirable feature in hypertension, and it seems logical that regression of hypertrophy might improve prognosis. However, clinical data to support this contention are sparse. Only one study has provided prospective evidence of the benefits of regression of left ventricular hypertrophy. Data from the Framingham study showed a fall of $25 \%$ in cardiovascular mortality in a subgroup with reduction in electrocardiographic left ventricular hypertrophy compared with a similar group without such regression during follow up of over four years. ${ }^{18}$ Furthermore, in 166 patients with hypertension followed up for five years cardiovascular events occurred in only $6 \%$ of those whose left ventricular mass decreased or was unchanged compared with $16 \%$ with increased left ventricular hypertrophy. ${ }^{19}$

\section{Mechanisms underlying left ventricular hypertrophy}

Cardiac myocytes hypertrophy in response to increased wall stress (tension), as occurs in hypertension. This hypertrophy of individual cells in turn results in left ventricular wall hypertrophy, which tends to reduce unit wall tension as predicted by the La Place equation $(\mathrm{T}=\mathrm{p} \times \mathrm{r} / 2 \mathrm{~L}$, where $\mathrm{T}=$ ventricular wall tension, $P=$ left ventricular pressure, $r=$ ventricular radius, and $\mathrm{L}=$ ventricular wall thickness). Increased tension is a direct stimulus to myocyte hypertrophy both in isolated tissue preparations ${ }^{20}$ and in intact hearts. ${ }^{21}$ These effects of tension on myocytes may be mediated by mechanotransducer ion channels, possibly by modifying intracellular $\mathrm{pH}$ or the concentration of intracellular messengers such as cyclic AMP, which in turn increase messenger RNA and protein production. Myocardial stretch may also increase messenger RNA directly by deforming the nucleus. ${ }^{22}$ Other evidence suggests, however, that additional neurohumoral factors modify the hypertrophic response to tension. Cardiac structure is influenced not only by haemodynamic load but also by diverse neurohumoral factors, including the renin-angiotensin system, $\alpha$ and $\beta$ adrenergic stimulation, and thyroxine. Different forms of antihypertensive treatment may therefore differ in their ability to promote regression of left ventricular hypertrophy, depending on their effects on neurohumoral factors in addition to their ability to lower blood pressure.

Angiotensin II and cardiac hypertrophy Angiotensin II may contribute to left ventricular hypertrophy through a range of different mechanisms. Firstly, it may make a significant contribution to total peripheral vascular resistance and hence to ventricular afterload in many forms of hypertension. Secondly, angiotensin II may indirectly stimulate myocyte hypertrophy by interacting with the sympathetic nervous system to augment sympathetic tone. ${ }^{22}$ Thirdly, angiotensin II has a direct trophic effect on mammalian myocytes, both as a circulating hormone and probably also through a local cardiac renin-angiotensin system. ${ }^{23}$ Fourthly, angiotensin II can stimulate fibroblast proliferation $^{24} 25$ and hence the formation of collagen. Angiotensin II stimulates DNA and RNA turnover in isolated myocytes, ${ }^{26}$ and protein synthesis is augmented within hours of exposure to angiotensin II. ${ }^{26-28}$ These effects seem to be modulated by protein kinase C, cytosolic calcium, and activation of growth modulating proto-oncogenes. ${ }^{23} 2930$

The relative importance of haemodynamic load as opposed to the renin-angiotensin system and other trophic hormones in the development of left ventricular hypertrophy has not been defined. The prevalence of left ventricular hypertrophy is high in essential hypertension in humans. The relation between blood pressure and indices of left ventricular mass are often statistically weak, but there seems little doubt that cardiac afterload in itself is a major determinant of left ventricular mass. This contention is supported by the fact that mean 24 hour blood pressure values from continuous ambulatory measurements relate more closely to left ventricular hypertrophy than do casual clinic blood pressure measurements. Furthermore, integrated blood pressures over 30 years were more clearly related to left ventricular mass geometry than were contemporary blood pressures in the Framingham heart study. ${ }^{31}$ With acquisition of full data over a long time to give an integrated measure of blood pressure and thus cardiac afterload, the relation with left ventricular mass will become more clear.

Nevertheless, other factors must be codeterminants. Positive statistical associations, which may or may not reflect cause and effect, have been noted between left ventricular mass and numerous indices, including dietary intake of sodium, ${ }^{32}{ }^{33}$ body weight $^{34}{ }^{35}$ or body build, ${ }^{36}$ blood viscosity, ${ }^{37}$ plasma catecholamine concentrations, ${ }^{38}$ and increasing age. ${ }^{39}$ In essential hypertension the degree of activation of the circulating renin-angiotensin system has been positively related, albeit rather 
weakly, to left ventricular hypertrophy. ${ }^{40-42}$ However, other reports are contradictory. For example, Russell et al reported that electrocardiographic left ventricular hypertrophy was less common in high renin than in normal renin essential hypertension. ${ }^{43}$ Hammond et al found that in patients with sustained hypertension low rather than high plasma renin activities were associated with left ventricular hypertrophy on echocardiography. ${ }^{44}$ Suzuki et al found that left ventricular mass and relative wall thickness were similar in patients with unilateral renovascular (high renin) hypertension and in patients matched for age, sex, and blood pressure who had primary (low renin activity) aldosteronism. ${ }^{45}$ The treatment of primary aldosteronism results in regression of left ventricular hypertrophy despite rising concentrations of renin and angiotensin II. $^{46}$ Hence, activation of the circulating reninangiotensin system is not an essential factor for expression of left ventricular hypertrophy in hypertension.

The role of the cardiac tissue reninangiotensin system in patients with left ventricular hypertrophy is unknown.

Alderman et al found that in patients with hypertension, renin profiles (obtained by plotting plasma renin activity against urinary excretion of sodium) were independently associated with subsequent risk of myocardial infarction. ${ }^{47}$ Other workers found no such association between plasma renin activity and myocardial infarction in normotensive men. ${ }^{48}$ This raises the question of whether the association of activation of the renin-angiotensin system and coronary events in essential hypertension is mediated by promotion of left ventricular hypertrophy.

A further link between the reninangiotensin-aldosterone system and cardiovascular risk has appeared in recent studies indicating that a particular deletion polymorphism in the angiotensin converting enzyme gene is associated with the risk of myocardial infarction, ischaemic cardiomyopathy, congestive cardiomyopathy, and hypertrophic cardiomyopathy. ${ }^{49-52}$ The association was particularly strong in patients with hypertrophic cardiomyopathy with a strong family history of sudden death. ${ }^{52}$ The DD polymorphism seems to act as an independent risk factor. This polymorphism is related to enhanced plasma activity of ACE. Presumably, this may correlate with increased plasma or tissue concentrations of angiotensin II, although this latter point remains uncertain. Hence, in vitro, in vivo, and clinical data link the renin-angiotension system with left ventricular hypertrophy and increased cardiovascular morbidity. This raises the question whether ACE inhibition may be especially effective in promoting regression of left ventricular hypertrophy and improving cardiovascular prognosis.

Animal studies

Lowering blood pressure by ACE inhibition in spontaneously hypertensive rats (and other animal models of hypertension) results in regression of left ventricular hypertrophy. ${ }^{53} 54$ Several workers have attempted to determine whether this is purely a pressure dependent phenomenon or whether ACE inhibitors have additional effects related to reduction in angiotensin II concentrations or to changes in other humoral agents.

Dostal and Baker infused angiotensin II into normotensive Sprague-Dawley rats for between 7 and 14 days. ${ }^{55}$ Left ventricular mass increased substantially. The specific angiotensin I receptor blocker losartan prevented this increase in left ventricular hypertrophy. When blood pressure was maintained in the normal range by concurrent administration of hydralazine with the angiotensin II, this did not prevent the induction of hypertrophy. In addition, in the first seven days of angiotensin II infusions many animals showed no rise in blood pressure and yet the left ventricle became hypertrophied. Infusion of angiotensin II during ACE inhibition (with perindopril) in spontaneously hypertensive rats not only prevented the antihypertensive effect of the ACE inhibitor but also resulted in the development of greater heart weights than in animals not receiving an ACE inhibitor. ${ }^{56}$ Whereas captopril and dihydralazine were equally effective in preventing a rise in blood pressure in spontaneously hypertensive rats, only the former limited cardiac hypertrophy. ${ }^{57}$ ACE inhibition in two kidney, one clip renovascular hypertension prevented the development of left ventricular hypertrophy ${ }^{58}$ and can lead to regression of established left ventricular hypertrophy, ${ }^{59-62}$ whereas alternative antihypertensive agents failed to do $\mathrm{so}^{63}$; minoxidil may actually induce ventricular hypertrophy in the renovascular model. ${ }^{61}$ The ACE inhibitor quinapril prevented left ventricular hypertrophy associated with intermittent hindquarter compression in dogs. Minoxidil failed to do so, despite its ability to lower blood pressure. ${ }^{64}$ These data suggest that angiotensin promotes left ventricular hypertrophy by mechanisms independent of its effects on blood pressure.

In contrast with these findings, Mooser et al studied relations between cardiac and renal hypertrophy and the circulating renin-angiotensin system in a low renin model of hypertension (desoxycorticosterone acetate-salt) and in the renin dependent two kidney, one clip model. ${ }^{65}$ Although the two models showed the expected difference in circulating reninangiotensin activity, the degree of left ventricular hypertrophy was similar in both hypertensive models, despite a trend to somewhat greater hypertension in the high renin model. Hence, left ventricular hypertrophy is related to increased ventricular load rather than to any independent effect of plasmaborne angiotensin II. Linz et al compared converting enzyme blockade with ramipril and angiotensin II receptor blockade with DUP 753 in an aortic banding model of hypertension in the rat. ${ }^{66}$ They found that the ACE inhibitor could prevent cardiac hypertrophy without much effect on blood pressure, 
while the angiotensin II receptor blocker did reduce blood pressure but was less effective in reducing cardiac hypertrophy. Further studies by this group indicated that ramipril was able to prevent left ventricular hypertrophy and myocardial fibrosis without blood pressure reduction over a one year period in rats. ${ }^{67}$ Both antihypertensive and non-antihypertensive doses were similarly effective in preventing cardiac hypertrophy and myocardial fibrosis. In rats with the volume expanded model of hypertension (desoxycorticosterone acetatesalt) ACE inhibition failed to reduce blood pressure or reverse left ventricular hypertrophy. ${ }^{68}$ By contrast, in rats rendered hypertensive by renal ablation and high salt intake perindopril prevented the usual increase in left ventricular weight, though circulating renin and angiotensin II values are low in this model, and did not attenuate the rise in arterial pressure. ${ }^{69}$ These studies suggest that a humoral effect independent of both reductions in blood pressure and suppression of angiotensin II may be responsible for at least part of the ability of converting enzyme inhibitors to induce regression of left ventricular hypertrophy.

Quinapril, an ACE inhibitor with high tissue penetrance, did not prevent increases in left ventricular mass in rats with supravalvar aortic stenosis when given immediately after surgery. ${ }^{70}$ It did induce an $80 \%$ regression of established hypertrophy of the left ventricle when given six weeks after the operation. In contrast, Zierhut et al observed no effects of ramipril on the development of left ventricular hypertrophy (or cellular hypertrophy) in rats with stenosis of the aortic arch. ${ }^{71}$

Thus animal data provide mixed messages. Angiotensin II may be able to induce left ventricular hypertrophy independent of its pressor effects, although data from different groups are conflicting. ${ }^{55} 656771$ ACE inhibition can clearly prevent left ventricular hypertrophy or induce regression of left ventricular hypertrophy in hypertensive rats, and this effect may be at least partially independent of reductions in blood pressure and involve additional humoral mechanisms - for example, bradykinin-beyond simple reduction in angiotensin II concentrations. Clearly, further careful controlled experiments in a range of species with left ventricular hypertrophy of varied aetiology are needed to clarify further the role of ACE inhibition in regression of left ventricular hypertrophy.

\section{Studies in human hypertension}

The findings of the review by Liebson ${ }^{72}$ and the meta-analyses by Cruickshank et $a l^{73}$ and Dahlöf et $a l^{74}{ }^{75}$ are essentially consistent in suggesting that ACE inhibition causes a greater regression of left ventricular hypertrophy for a given fall in blood pressure than do other simple drug treatments; ACE inhibition may be as effective in this regard as combination treatments. However, all the authors appropriately point out several weaknesses in the database from which these possible conclusions are derived.
The available analyses must be interpreted with four points in mind.

(1) Most studies of drug reversal of left ventricular hypertrophy in hypertension are uncontrolled.

(2) The number of patients in each study is generally small.

(3) In most studies the mean degree of left ventricular hypertrophy present is not great, and results may thus be distorted by inclusion of large numbers of patients who will not show regression of left ventricular hypertrophy simply because the condition is not present.

(4) It is possible that there are many studies with negative results that have not been published.

Liebson reviewed over 60 clinical studies using echocardiographic measurement of left ventricular mass. On average, only 10-15 subjects were included in each study. $\mathrm{He}$ pointed out the lack of studies in patients with clearly established disease-that is, clearcut moderate or severe left ventricular hypertrophy with complications such as coronary disease-and highlighted the need for a study which followed up a substantial number of people over a long treatment period. Ninety per cent of studies had a follow up period of less than one year. The longest running study with the largest number followed up in a single study (68 patients followed up for five years) was published by Schlant et al in 1982. ${ }^{76}$

At the time of Liebson's review in 1990 only three of 66 studies available for analysis included a placebo group. Only three studies used ACE inhibition as the primary treatment, and this included only 35 patients. Notwithstanding these clear limitations, ACE inhibitors and calcium channel antagonists more reliably induced reduction of left ventricular mass than $\beta$ blockade (where it occurred in $50 \%$ ), diuretics (much less than $50 \%$ ), or peripheral vasodilators (less than $50 \%$ ). This review also reported that there was no evidence of a loss of left ventricular contractile systolic function with regression of left ventricular hypertrophy. Nearly all the patients recruited into these studies had no underlying significant heart disease other than possible mild to moderate left ventricular hypertrophy. Clearly, it is important to determine whether regression of left ventricular hypertrophy produced major mechanical disadvantages in patients who have already sustained major cardiac ischaemic events or have other associated cardiac lesions beyond the hypertrophy.

The first reports indicating regression of left ventricular hypertrophy in hypertension treated with ACE inhibitors appeared in the early 1980s. Typically they included a small number of patients followed up for fairly brief periods of time without a control group for comparison. For example, Fouad et al followed up 10 patients treated with enalapril over 3-7 months using both radionuclide and echocardiographic measurements of left ventricular mass and function; six out of seven patients showed regression of left ventricular hypertrophy, and left ventricular function 
remained excellent. ${ }^{77}$ Dunn et al followed up eight patients treated with enalapril for only 12 weeks and found a significant reduction in left ventricular mass index and no impairment of left ventricular contractility. ${ }^{78}$ Nakashima et al studied seven patients receiving enalapril and undergoing echocardiography and radionuclide studies at baseline, at 5 days, and after one, three, and seven months of treatment. ${ }^{79}$ Left ventricular mas was reduced significantly at three and seven months by $10 \%$ and $12 \%$ respectively. At the time these three small studies and several others were published in the early 1980 s only methyldopa and $\beta$ blocking drugs had been reported as inducing regression of left ventricular hypertrophy when used as a single treatment in hypertension. ${ }^{80-83}$ Previously, when combination treatment had been seen to induce regression of left ventricular hypertrophy, the combination almost always included a sympatholytic agent or a $\beta$ blocker. ${ }^{84-86}$

Few data are available comparing the effects of different ACE inhibitors. Garavaglia et al studied 30 patients with mild to moderate hypertension receiving captopril, lisinopril, or enalapril for 10-12 weeks. ${ }^{87}$ Left ventricular mass was reduced in all three groups but rather more with enalapril $(29 \%)$ than with either of the two other agents $(14 \%$ and $12 \%$ respectively). But the number of subjects in each group was small (8-12) and baseline values for left ventricular mass were greatest in the enalapril group. Grandi et al found that captopril and perindopril had similar effects on both blood pressure and left ventricular mass. ${ }^{88}$ Hence, as yet, there are no unequivocal data indicating that any particular ACE inhibitor or class of ACE inhibitors is superior to another in terms of the ability to induce regression of left ventricular hypertrophy.

Although numerous studies indicate that regression of left ventricular hypertrophy does not lead to any impairment in left ventricular systolic contractile function during treatment, ${ }^{77-79}$ most studies do not address the question of whether the "regressed" ventricle is more prone to dysfunction with the challenge of acute increments in blood pressure without the mechanical advantage of hypertrophy, which reduces unit wall stress. One of the few studies to address this point was conducted by Schmieder et al, who performed an open study in 14 subjects receiving $\beta$ blockade (five), calcium antagonists (two), or converting enzyme inhibitors (four). ${ }^{89} \mathrm{~A}$ further three received a combination of $\beta$ blocker and diuretic. Left ventricular mass was significantly reduced from 274 (24) g to 239 (18) g over an average of 19 months of treatment. After this period of treatment drugs were removed for four weeks, during which blood pressure returned to pretreatment values. Echocardiography indicated that the ventricles performed normally despite the loss of left ventricular mass. As in many other studies, patients in this study had minimal baseline increases in mean posterior wall thickness or interventricular septal thickness, indicating that probably half the people studied did not satisfy criteria for left ventricular hypertrophy. The question remains whether regression of pronounced established left ventricular hypertrophy with or without complicating coronary or other cardiac disease renders ventricles vulnerable to dysfunction in the advent of short term changes in blood pressure.

Schneeweiss et al have published one of the few blinded comparative studies of a substantial number of patients. ${ }^{90}$ Thirty patients with hypertension were treated with either cilazapril or hydrochlorothiazide for 10 weeks. Within this time the ACE inhibitor induced some regression of left ventricular hypertrophy but the thiazide agent did not, despite similar effects on blood pressure.

In one of the few studies that specifically examined patients with clearly established left ventricular hypertrophy 34 patients, all with poorly controlled blood pressure despite treatment with a $\beta$ blocker and diuretic, had either captopril or minoxidil randomly added to their treatment. ${ }^{91}$ Mean interventricular septal thickness was $17.4 \mathrm{~mm}$ and $15.5 \mathrm{~mm}$ for the captopril and minoxidil groups respectively. Posterior wall thickness was $14.5 \mathrm{~mm}$ and $14.1 \mathrm{~mm}$ respectively. Left ventricular mass index was $236 \mathrm{~g} / \mathrm{m}^{2}$ and $212 \mathrm{~g} / \mathrm{m}^{2}$ for the two groups. Thus severe left ventricular hypertrophy was present. Baseline blood pressures were similar in the two groups. Left ventricular wall thickness and mass index clearly declined in the group treated with captopril, whereas the opposite occurred in those receiving minoxidil despite similar reductions in blood pressure. These data contrast the effect of an ACE inhibitor against minoxidil when both were combined with two other antihypertensive agents. Nevertheless, the differences in response are quite striking.

At least one study suggests that the ability of ACE inhibitors to induce regression of left ventricular hypertrophy is independent of cardiac innervation. Angermann et al reported regression of left ventricular hypertrophy on echocardiography in 10 patients with hypertension after cardiac transplantation. ${ }^{92}$ Treatment over one year with enalapril and frusemide with or without verapamil reduced blood pressure substantially and significantly reduced left ventricular mass.

With the shortcomings of previous studies in mind, Dahlöf and Hansson compared enalapril and hydrochlorothiazide in a double blind study of treatment with hypertension in male patients who were previously untreated. ${ }^{93}$ This was a double blind comparative trial without a placebo group. Twenty eight patients were included. Treatment was maintained for 14-18 months. Similar reductions in blood pressure occurred with both drugs. Left ventricular mass fell progressively and significantly after 18 months of treatment with enalapril. In comparison, reductions in left ventricular mass with hydrochlorothiazide were not significant. Neither drug had an adverse effect on systolic left ventricular function. Enalapril significantly reduced posterior left ventricular wall thickness, inter- 
ventricular septal thickness, and left ventricular mass. The authors concluded that an ACE inhibitor is significantly more effective than a diuretic in reducing left ventricular mass. Before this study trials of ACE inhibition were confined to open studies usually in previously treated patients. Despite its strengths, the study by Dahlöf and Hansson still includes only 28 patients, or 14 in each study group, and once again mean baseline values for ventricular dimensions and mass suggest that much of the study group did not have left ventricular hypertrophy. There is clearly still a major need for a carefully conducted double blind comparative study (a true placebo group is ethically prohibited) with follow up of at least one year of patients with well established left ventricular hypertrophy at baseline. Similarly, studies of those with hypertensive left ventricular hypertrophy and other established cardiac disease are also required.

Not all clinical trials examining the effect of ACE inhibitors in hypertension with left ventricular hypertrophy have positive results. In view of the described frailties of the database and the probability that studies with negative results are not as readily published as those with positive results, these contrary findings cannot be ignored. Shahi et al studied 20 previously untreated hypertensive patients receiving captopril with or without a diuretic for six months and found reduced blood pressure $(15 / 20)$ without change in left ventricular hypertrophy. ${ }^{94}$ However, mean baseline left ventricular dimensions were not obviously hypertrophic, although indices of diastolic function (criteria for selection to the study) were uniformly abnormal. Recently, Laufer $e t$ al found no change in left ventricular hypertrophy, despite sustained falls in blood pressures, in patients treated with either captopril or atenolol for 12 months (15th scientific meeting of the High Blood Pressure Research Council of Australia, Melbourne, December 1993).

The conclusions of meta-analyses by Cruickshank et $a l^{73}$ and Dahlöf et al ${ }^{74}{ }^{75}$ must be considered in light of the limitations of the database as already described. Cruickshank et al analysed data from 104 published studies. ${ }^{73}$ Of these, only eight were randomised and placebo controlled. Twenty two were randomised and were comparisons of active treatments, and most (74) were uncontrolled studies. The analysis used all data and compared results in each treatment subgroup with its own baseline data, yielding a total of 147 sets of data for comparisons over time. Interestingly, the authors found that change in heart rate and the degree of left ventricular hypertrophy at baseline was not significantly associated with outcome, and these cofactors were dropped from analyses. A clear possible flaw in this form of analysis resides in the fact that if the vast majority of study participants did not have true left ventricular hypertrophy, the full predictive effect of baseline left ventricular hypertrophy may be "diluted" and become statistically inapparent. On average, the change in blood pressure (irrespective of the form of drug treatment) and the duration of treatment were related to the change in left ventricular mass.

When we wrote this review, the number of studies fulfilling criteria for inclusion in the meta-analysis and the total number of patients included in trials of treatment with ACE inhibition had risen (compared with the 1990 review by Leibson ${ }^{72}$ ) to 23 studies including 321 patients receiving either captopril or enalapril. However, in the total patient pool of 2107 patients only 76 were in placebo groups. The mean duration of treatment with ACE inhibitors was $7 \cdot 0$ months, the maximum being 12 months. The mean reduction in mean arterial pressure with ACE inhibition was $22 \mathrm{~mm} \mathrm{Hg}$, which was greater than any other single group other than combination drug treatment, although this distinction was not significant. Left ventricular mass index analysed for all active treatment fell significantly. This was not true for the placebo group, but the numbers taking placebo were small, reducing the statistical power of this subanalysis.

There were significant differences between active drug classes in change in left ventricular dimensions and mass. When the effects of the fall in blood pressure and duration of treatment were taken into account, the distinctions between drugs in terms of change in left ventricular wall thickness were lost, but an effect on change in left ventricular mass index was preserved. By multivariate analysis the change in left ventricular mass index differed between drugs, this distinction being independent of the degree of left ventricular hypertrophy, the degree of blood pressure reduction, and time receiving treatment. ACE inhibitors reduced left ventricular mass more than vasodilators or dihydropyridine calcium antagonists or $\beta$ blockers. The effect of ACE inhibitors was comparable with that of methyldopa. Among drug groups, the relation between change in blood pressure and change in left ventricular mass was most pronounced for $\beta$ blockers. The duration of studies using calcium antagonists tended to be short $(4 \cdot 1$ months on average), thus possibly disadvantaging calcium antagonists in analysis, but when similarly brief ACE inhibitor studies were compared with calcium antagonist studies a superior effect of ACE inhibition in left ventricular mass reduction was still observed.

Currently, the recent meta-analysis by Dahlöf et al represents the current state of knowledge on the relative strength of antihypertensive drugs in regression of left ventricular hypertrophy. ${ }^{74}$ This metaanalysis considers studies published from 1977 up to the end of 1990, which gave data concerning reversal of left ventricular hypertrophy assessed by echocardiography. Studies were included in the analysis if all recruited patients had essential (as opposed to secondary or malignant) hypertension; if patients were treated with drugs (rather than given non-pharmacological treatment); if 
patients underwent standardised echocardiography; if patients were all accounted for (studies with a fall out rate $>30 \%$ were excluded); and if the data had been published in "reputable" journals with peer review or "similar editorial processes." The analysis included 14 studies of ACE inhibitors with an average study group size of $11 \cdot 2$-that is, a total of 157 patients. Thus it is more selective than that by Cruickshank et al published in the same year, which included a slightly smaller number of studies (104 $v 109)$ but a greater number of patients receiving ACE inhibitors (321 v 157)..$^{73}$ Overall, 2357 patients were included in analysis. Twenty eight per cent of these were previously untreated. Studies with ACE inhibition included only $11 \%$ previously untreated patients. Diuretic studies included $55 \%$, calcium antagonists $22 \%$, and $\beta$ blockers $20 \%$. This disparity would tend to bias the study against indicating a superior effect for ACE inhibitors rather than otherwise (see below).

Overall, active treatment of any kind reduced left ventricular mass by $11.9 \%(95 \%$ confidence interval $10 \cdot 1 \%$ to $13 \cdot 7 \%$ ), together with a fall in mean arterial pressure of $14.9 \%$ $(14 \cdot 0 \%$ to $15 \cdot 8 \%)$. ACE inhibitors reduced left ventricular mass by $15 \%(9 \cdot 9 \%$ to $20 \cdot 1 \%$ ), $\beta$ blockers by $8 \%(4 \cdot 8 \%$ to $11 \cdot 2 \%)$, calcium antagonists by $8 \cdot 5 \%(5 \cdot 1 \%$ to $11 \cdot 8 \%)$, and diuretics by $11 \cdot 3 \%$ ( $5 \cdot 6 \%$ to $17 \cdot 0 \%$ ). Mean fall in left ventricular mass was $44.7 \mathrm{~g}$ with ACE inhibitors, $22.8 \mathrm{~g}$ with $\beta$ blockers, 26.9 $\mathrm{g}$ with calcium antagonists, and $21.4 \mathrm{~g}$ with diuretics. All agents other than diuretics reduced left ventricular wall thickness while diuretics predominantly reduced ventricular diameter.

Only three studies in the meta-analysis were randomised, double blind, and exclusively studied previously untreated patients. Examination of data solely from previously untreated patients indicated greater average effects than in previously treated patients. Left ventricular mass was reduced by $15 \cdot 2 \%$ $(11 \cdot 3 \%$ to $18 \cdot 8 \%)$ and mean arterial pressure by $17 \cdot 2 \%$ (15.6\% to $18 \cdot 8 \%$ ). In previously untreated patients mean reduction in left ventricular mass associated with $\mathrm{ACE}$ inhibition was $16.9 \%(11 \cdot 6 \%$ to $22 \cdot 2 \%)$. This mean value was greater than that observed in any other subgroup, with the exception of the patients included under "all other monotherapies." The latter presumably included those treated with lesser used drugs and nonpharmacological treatments. This subgroup included some 300 patients who achieved a mean percentage reduction in left ventricular mass of $17 \%(9 \cdot 2 \%$ to $23 \cdot 8 \%)$. The subgroup included under "all combination therapies" also performed similarly to that under ACE inhibitors, with a reduction in left ventricular mass of $16 \cdot 4 \%(12 \cdot 6 \%$ to $20 \cdot 2 \%)$. The mean percentage reduction in mean arterial pressure was greater for ACE inhibition than any other subgroup $(16 \cdot 3 \%(3.6 \%))$. These distinctions between ACE inhibitors and other active treatments were not, however, significant in this meta-analysis. Furthermore, when co-

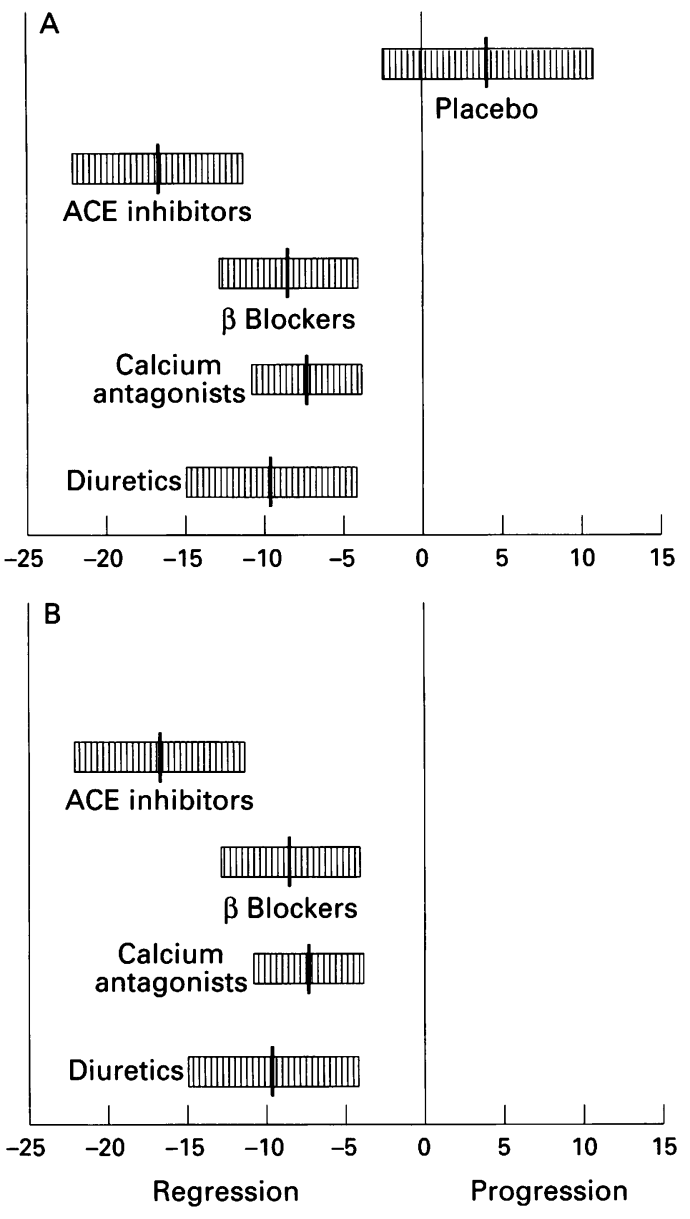

A: The unadjusted change in percentage of left ventricular mass with $95 \%$ confidence interval for placebo, $A C E$ inhibitors, $\beta$ blockers, calcium antagonists, and diuretics. $B:$ The adjusted change in percentage of left ventricular mass with 95\% confidence interval (ANCOVA) for ACE inhibitors, $\beta$ blockers, calcium antagonists, and diuretics.

variate analysis was applied to compensate for differences between studies in mean baseline indices of cardiac structure and in duration of follow up, the adjusted percentage change in left ventricular mass showed clear overlap in confidence intervals between ACE inhibitors, $\beta$ blockers, calcium antagonists, and diuretics (figure). Thus, although this meta-analysis provides strong suggestive evidence, based on trends, of an enhanced effect of ACE inhibition on regression of left ventricular hypertrophy, the data are by no means conclusive. The authors' cautious interpretation, "We hypothesize that ACE inhibitors are more effective than other first-line therapies in reducing [left ventricular] mass. However, this theory and its possible prognostic implications need to be evaluated in controlled prospective trials," seems appropriate.

\section{Conclusions}

In hypertension ACE inhibitors have theoretical advantages in terms of their neutral or benign effect on glucose and lipid metabolism; the possible protective effects against recurrent myocardial infarction in patients who have had an infarction; their possible special efficacy in preserving renal function in diabetes; and their safety and value when other conditions, such 
as asthma or heart failure, coexist with hypertension. Current data suggest that ACE inhibitors are probably superior to other antihypertensive agents in promoting regression of left ventricular hypertrophy. However, carefully designed, blinded, randomised trials comparing ACE inhibitors with other agents for at least 12 months in previously untreated patients with established left ventricular hypertrophy are still required before this added advantage can be unequivocally added to the growing list of therapeutic benefits offered by ACE inhibitors. Additional studies should focus on groups with hypertension with left ventricular hypertrophy and other established cardiac disease.

Mrs Barbara Griffin provided expert secretarial help

1 Frohlich ED, Apstein A, Chobanian AV, Devereux RB, Dustan HP, Dzau V, et al. The heart in hypertension. $N$ Engl f Med 1992;327:998-1008.

2 Kannel WB, Doyle JT, McNamara PM, Quickenton P, Cordon T. Precursors of sudden coronary death: factors related to the incidence of sudden death. Circulation 1975;51:606-13.

3 Messerli FH, Ventura HO, Elizardi DJ, Dunn FG, Frohlich ED. Hypertension and sudden death: increased ventricular ectopic activity in left ventricular hypertrophy. Am $\mathcal{F}$ Med 1984;77:18-22.

4 McLenachan JM, Henderson E, Morris KI, Dargie HJ. Ventricular arrhythmias in patients with hypertensive left ventricular hypertrophy. $N$ Engl $\mathfrak{f}$ Med 1987; ventricular

5 Levy D, Anderson JM, Plehn J, Savage DD, Christiansen JC, Castelli WP. Echocardiographically determined left JC, Castelli WP. Echocardiographically determined left ventricular structural and functional correlates of
complex or frequent ventricular arrhythmias on one-hour complex or frequent ventricular arrhythmias on one-hour
ambulatory electrocardiographic monitoring. $A m \quad \mathcal{J}$ ambulatory electrocardiog

6 Dunn FG, Pringle SD. Left ventricular hypertrophy and myocardial ischemia in systemic hypertension. $A m \mathcal{J}$ Cardiol 1987;60:191-221.

7 Kannel WB, Gordon T, Castelli WP, Margolis JR. Electrocardiographic left ventricular hypertrophy and risk of coronary heart disease: the Framingham study. Ann Intern Med 1970;72:813-22.

8 Levy D, Garrison RJ, Savage DD, Kannel WB, Castelli WP. Left ventricular mass and incidence of coronary heart disease in an elderly cohort: the Framingham heart study. Ann Intern Med 1989;110:101-7.

9 Levy D, Garrison RJ, Savage DD, Kannel WB, Castelli WP. Prognostic implications of echocardiographically determined left ventricular mass in the Framingham heart study. N Engl F Med 1990;322:1561-6.

10 Levy D, Labib SB, Anderson KM, Christiansen JC, Kannel WB, Castelli WP. Determinants of sensitivity and specificity of electrocardiographic criteria for left ventricular hypertrophy. Circulation 1990;81:815-20.

11 Levy D, Savage DD, Garrison RJ, Anderson KM, Kannel WB, Castelli WP. Echocardiographic criteria for left ventricular hypertrophy: the Framingham heart study. ventricular hypertrophy: the Fran

12 Devereux RB, Reichek N. Echocardiographic determination of left ventricular mass in man. Anatomic validation of the method. Circulation 1977;55:613-8.

13 Devereux RB, Lutas EM, Casale PN, Kligfield P, Eisenberg $\mathrm{RR}$, Hammond IW, et al. Standardization of M-mode echocardiographic left ventricular anatomic measurements. FACC 1984;4:1222-30.

14 Devereux RB, Alonso DR, Lutas EM, Gottlieb GJ, Campo E, Sach I, et al. Echocardiographic assessment of left ventricular hypertrophy: comparison to necropsy findings. Am $\mathcal{F}$ Cardiol 1986;57:450-8.

15 Koren MJ, Devereux RB, Castle PN, Savage DD, Laragh $\mathrm{JH}$. Relations of left ventricular mass and geometry to morbidity and mortality in uncomplicated essential hypertension. Ann Intern Med 1991;114:345-52.

16 Sullivan JM, Zwaag RV, El-Zeky F, Ramanathan KB, Mirvis DM. Left ventricular hypertrophy: effect on survival. $7 A C C$ 1993;22:508-13.

17 Dunn FG, McLenachan J, Isles CG, Brown I, Dargie HJ, Lever AF, et al. Left ventricular hypertrophy and mortality in hypertension: an analysis of data from the 8:775-82.

18 Kannel WB, D'Agostino RB, Levy D, Belanger AJ. Prognostic significance of regression of left ventricular hypernostic significance of regression of left ventricular hyp
trophy [abstract]. Circulation 1988;78(suppl II):II89.

19 Koren MJ, Ulin RJ, Laragh JH, Devereux RB. Reduction of LVM during treatment of essential hypertension is of LVM during treatment of essential hypertension is associated with improved prognosis. Am f Hypertens of Hypertension, New York, May 1991.)

20 Kent RL, Hoober JK, Cooper G. Load responsiveness of protein synthesis in adult mammalian myocardium: role of cardiac deformation linked to sodium influx. Circ Res 1989;64:74-85

21 Kira Y, Kochel PJ, Gordon EE, Morgan HE. Aortic perfusion pressure as a determinant of cardiac protein synthesis. Am f Physiol 1984;246:C427-C258.

22 Morgan HE, Baker KM. Cardiac hypertrophy. Mechanical, neural and endocrine dependence. Circulation 1991; 83:13-25.

23 Pratt RE, Dzau VJ. Trophic effects of angiotensin on blood vessels and heart. In: Robertson JIS, Nicholls MG, eds. The renin-angiotensin system. Vol 1. London: Gower, 1993:31.1-7.

24 Weber KT, Janicki JS. Angiotensin and the remodelling of the myocardium. $\mathrm{Br} f$ Clin Pharmacol 1989;28: 141-50S.

25 Ganten D, Schelling P, Flugel RM, Ganten U. Effect of angiotensin and an angiotensin antagonist on iso-renin angiotensin and an angiotensin antagonist on iso-renin Communications in the Medical Sciences 1975;3:327-32.

26 Khairallah PA, Robertson AL, Davila D. Effects of angiotensin II on DNA, RNA and protein synthesis. In: Genest J, Loiw E, eds. Hypertension. New York: Springer, 1972:212-8.

27 Asceto JF, Baker KM. [Sar'] angiotensin II receptormediated stimulation of protein synthesis in chick heart cells. Am f Physiol 1990;258:H806-13.

28 Baker KM, Aceto JF. Angiotensin II stimulation of protein synthesis and cell growth in chick heart cells. $A m \mathcal{F}$ Physiol 1990;259:H610-8.

29 Hoh E, Komuro I, Kurabayshi M, Katoh Y, Shibazaki Y, Yazaki Y. The molecular mechanism of angiotensin IIinduced c-fos gene expression on rat cardiomyocytes [abstract]. Circulation 1990;82(suppl III):351.

30 Izumo S, Nadal-Ginard B, Mahdavi V. Proto-oncogene induction and reprogramming of cardiac gene expression produced by pressure overload. Proc Natl Acad Sci USA 1988;85:339-43.

31 Lauer MS, Anderson KM, Levy D. Influence of contemporary versus 30-year blood pressure levels on left
ventricular mass and geometry: the Framingham heart ventricular mass and geometry:
study. $¥ A C C$ 1991;18:1287-94.

32 du Cailar J, Ribstein J, Grolleau R, Mimran A. Influence of sodium intake on left ventricular structure in untreated essential hypertensives. F Hypertens 1989;7:S258-9.

33 Schmieder RE, Messerli FH, Garavaglia FE, Nunez BD. Dietary salt intake. A determinant of cardiac involvement in essential hypertension. Circulation 1988;78:951-6.

34 Egan B, Fitzpatrick MA, Juni J, Buda AJ, Zweifler A. Importance of overweight in studies of left ventricular hypertrophy and diastolic function in mild systemic hypertension. Am f Cardiol 1989;64:752-5.

35 Suurkula MB, Wikstrand J, Berglund G, Sivertsson R. Body weight is more important than family history of hypertension for left ventricular function. Hypertension 1991;17:661-8.

36 McLenachan JM, Henderson E, Morris KI, Dargie HJ. Electrocardiographic diagnosis of left ventricular hyper-
trophy: influence of body build. Clin Sci 1988; 75:589-92.

37 Devereux RB, Drayer JIM, Chien S, Pickering TG, Letcher $\mathrm{RL}$, DeYoung JL, et al. Whole blood viscosity as a determinant of cardiac hypertrophy in systemic hypertension. Am f Cardiol 1984;54:592-5.

38 Trimarco B, Ricciardelli B, De Luca N, De Simone A, Cuocolo A, Galva MD, et al. Participation of endogenous
catecholamines in the regulation of left ventricular mass in progeny of hypertensive patients. Circulation 1985; in progen

39 Tuzcu EM, Golz SJ, Lever HM, Salcedo EE. Left ventricular hypertrophy in persons aged 90 years and ventricular hypertrophy in persons a
older. Am 7 Cardiol 1989;63:237-40.

40 Jorgensen $\mathrm{H}$, Sundsfiord JA. The relation of plasma renin activity to left ventricular hypertrophy and retinopathy in patients with arterial hypertension. Acta Med Scand 1974;196:307-13

41 Schmieder RE, Messerli FH, Garavaglia GE, Nunez B, MacPhee AA, Re RN. Does the renin-angiotensinaldosterone system modify cardiac structure and function in essential hypertension? $A m \mathcal{F}$ Med 1988;84(suppl 3A): $136-41$.

42 Bauwens FR, Duprez DA, Buyzere ML, De Backer TL, Kaufman JM, Van Hoecke J, et al. Influence of the arterial blood pressure and nonhemo-dynamic factors on left ventricular hypertrophy in moderate essential hypertension. Am $\mathcal{F}$ Cardiol 1991;68:925-9.

43 Russell GI, Bing RF, Thurston H, Swales JD. Plasma renin in hypertensive patients: significance in relation to clinical and other biochemical features. $Q 7 \mathrm{fmed}$ 1980;49:385-94.

44 Hammond IW, Devereux RB, Alderman MH, Lutas EM, Spitzer MC, Crowley JS, et al. The prevalence and correlates of echocardiographic left ventricular hypertrophy among employed patients with uncomplicated trophy among employed patients

45 Suzuki T, Abe H, Nagata S, Saitoh F, Iwata S, Ashizawa $\mathrm{A}$, et al. Left ventricular structural characteristics in unilateral renovascular hypertension and primary unilateral renovascular hypertension and

46 Pringle SD, Macfarlane PW, Isles CG, Cameron HL, Brown IA, Lorimer AR, et al. Regression of electroBrown IA, Lorimer AR, et al. Regression of electrocardiographic left ventricular hypertrophy following
treatment of primary hyperaldosteronism. $\mathfrak{f}$ Hum treatment of primary
Hypertens $1988 ; 2: 157-9$. 
47 Alderman MH, Madhavan S, Ooi WL, Cohen H, Sealey $\mathrm{JE}$, Laragh $\mathrm{JH}$. Association of the renin-sodium profile with the risk of myocardial infarction in patients with hypertension. N Engl f Med 1991;324:1098-104.

48 Meade TW, Cooper JA, Peart WS. Plasma renin activity and ischemic heart disease. $N$ Engl f Med 1993; 329:616-9.

49 Tiret L, Kee F, Poirier O, Nicaud V, Lecerf L, Evans A, et al. Deletion polymorphism in angiotensin-converting enzyme gene associated with parental history of myocardial infarction. Lancet 1993;341:991-2.

50 Cambien F, Poirier O, Lecerf L, Evans A, Cambou JP, Arveiler D, et al. Deletion polymorphism in the gene for angiotensin-converting enzyme is a potent risk factor for angiotensin-converting enzyme is a potent risk

51 Raynolds MV, Bristow MR, Bush EW, Abraham WT, Lowes BD, Zisman LS, et al. Angiotensin-converting enzyme DD genotype in patients with ischaemic or idiopathic dilated cardiomyopathy. Lancet 1993;342: 1073-5.

52 Marian AJ, Yu Q, Workman R, Greve G, Roberts R. Angiotensin-converting enzyme polymorphism in hypertrophic cardiomyopathy and sudden cardiac death Lancet 1993;342:1085-6.

53 Sen S, Tarazi RC, Bumpus $M$. Effect of converting enzyme inhibitor (SQ14,225) on myocardial hypertrophy in spontaneously hypertensive rats. Hypertension 1980 2:160-76.

54 Kuzuo $\mathrm{H}$, Honda $\mathrm{M}$, Ishinaga $\mathrm{Y}$, Morioka $\mathrm{S}$, Tanaka $\mathrm{K}$, Kuramochi $\mathrm{T}$, et al. Angiotensin concerting enzyme inhibitor, captopril, inhibits cardiac hypertrophy without changing collagen types and concentration in spontaneously hypertensive rats. Clin Exp Pharmacol Physiol 1993;20:253-60.

55 Dostal DE, Baker KM. Angiotensin II stimulation of left ventricular hypertrophy in adult rat heart. Am $\mathcal{f}$ Hyperten 1992;5:276-80.

56 Harrap SB, Van der Merwe WM, Griffin SA, Macpherson $\mathrm{F}$, Lever AF. Brief angiotensin converting enzym inhibitor treatment in young spontaneously hypertensive rats reduces blood pressure long-term. Hypertensio 1990;16:603-14

57 Freslon JL, Giudicelli JF, Compared myocardial and vascular effects of captopril and dihydralazine during hypertension development in spontaneously hypertensive rats. Br f Clin Pharmacol 1983;80:533-43.

58 Jalil JE, Janicki JS, Pick R, Weber KT. Coronary vascula remodeling and myocardial fibrosis in the rat with renovascular hypertension. Response to captopril. $A m g$ Hypertens 1991;4:51-5.

59 Michel J-B. Relationship between decrease in afterload and beneficial effects of ACE inhibitors in experimental cardiac hypertrophy and conges

60 Sen S, Young DR. Role of sodium in modulation of myocardial hypertrophy in renal hypertensive rats. Hypertension 1986;8:18-24.

61 Leenen FHH, Prowse S. Time-course of changes in cardiac hypertrophy and pressor mechanisms in two-kidney, one clip hypertensive rats during treatment with minoxidil, enalapril or after uninephrectomy. 7 Hypertens 1987 ; 5:73-83.

62 Pauletto P, Nascimben L, Piccolo D, Secchiero S, Vescovo $\mathrm{G}$, Scannapieco $\mathrm{G}$, et al. Ventricular myosin and creatine-kinase isoenzymes in hypertensive rats treated with captopril. Hypertension 1989;14:556-62

63 Dussaule J-C, Michel J-B, Auzan C, Schwartz K, Corvol P, Menard J. Effect of antihypertensive treatment on the lef ventricular isomyosin profile in one-clip, two kidney, hypertensive rats. $f$ Pharmacol Exp Ther 1986; 236:512-8.

64 Julius S, Li Y, Brandt D, Krause L, Taylor D. Quinapril, an angiotensin converting enzyme inhibitor, prevents cardiac hypertrophy during episodic hypertension. Hypertension 1991;17:1161-6.

65 Mooser V, Katopothis A, Casley D, Johnston CI. Cardiac and renal hypertrophy is independent of tissue angiotensin converting enzyme and circulating angiotensin II in hypertensive rats. f Hypertens 1991;9(suppl 6): in hypert

66 Linz W, Henning R, Schölkens BA. Role of antiogensin II receptor antagonism and converting enzyme inhibition in the progression and regression of cardiac hypertrophy in rats. 7 Hypertens 1991;9(suppl 6):S400-1.

67 Linz W, Schaper J, Wiemer G, Albus U, Schölkens BA Ramipril prevents left ventricular hypertrophy with myocardial fibrosis without blood pressure reduction: a one year study in rats. Br f Pharmacol 1992;107:970-5.

68 Michel J-B, Salzmann J-L, Cerol M de L, Dussaule J-C, Azizi M, Corman B, et al. Myocardial effect of converting enzyme inhibition in hypertensive and normotensive rats. Am f Med 1988;84(suppl 3A):12-21.

69 Nakamura F, Nagano M, Higaki J, Higashimori $K$, Katahira K, Morishita R, et al. Regression of left ventricular hypertrophy by angiotensin converting enzyme inhibitor in reduced renal mass hypertensive rats. f Hypertens $1991 ; 9$ (suppl 6):S398-9.
70 Kromer EP, Elsner D, Riegger GAJ. Role of neurohumoral systems for pressure induced left ventricular hypertroph in experimental supravalvular aortic stenosis in rats. $A m$ f Hypertens 1991;4:521-4.

71 Zierhut W, Zimmer H-G, Gerdes AM. Effect of angiotensin converting enzyme inhibition on pressure-induced eft ventricular hypertrophy in rats. Circ Res 1991; 69:609-17.

72 Liebson PR. Clinical studies of drug reversal of hypertensive left ventricular hypertrophy. Am $\mathcal{F}$ Hypertens hypertensive

73 Cruickshank JM, Lewis J, Moore V, Dodd C. Reversibility of left ventricular hypertrophy by differing types of antiof left ventricular hypertrophy by differing types of ant-

74 Dahlöf B, Pennert K, Hansson L. Regression of left ventricular hypertrophy-a meta-analysis. Clin Exp ventricular hypertrophy-a met

75 Dahlöf B, Pennert K, Hansson L. Reversal of left ventricular hypertrophy in hypertensive patients. $A m \mathcal{F}$ Hypertens 1992;5:95-110.

76 Schlant RC, Felner JM, Blumenstein BA, Wollam GL, Hall WD, Shulman NB, et al. Echocardiographic documentation of regression of left ventricular hypertrophy in patients treated with essential hypertension. Eur Heart $\mathcal{F}$ 1982;suppl A: 171-5.

77 Fouad FM, Tarazi RC, Bravo EL. Cardiac and haemodynamic effects of enalapril. I Hypertens Suppl 1983;1:135-42.

78 Dunn FG, Oigman W, Ventura HO, Messerli FH, Kobrin I, Frohlich ED. Enalapril improves systemic and renal hemodynamics and allows regression of left ventricular mass in essential hypertension. Am 7 Cardiol 1984, 53:105-8.

79 Nakashima Y, Fouad FM, Tarazi RC. Regression of left ventricular hypertrophy from systemic hypertension by ventricular hypertrophy from systemic hypertension by

80 Fouad FM, Nakashima Y, Tarazi RC, Salcedo EE Reversal of left ventricular hypertrophy in hypertensive patients treated with methyldopa. Am $\mathcal{f}$ Cardiol $1982 ; 49 \cdot 795-801$.

81 Ibrahim MM, Madkour MA, Mossallam R. Factors influencing cardiac hypertrophy in hypertensive patients. Clin $S_{c i} 1981 ; 61: 105-8 \mathrm{~s}$.

82 Drayer JIM, Gardin JM, Weber MA, Aronow WS. Cardiac muscle mass during vasodilation therapy of hypertension. Clin Pharmacol Ther 1983;33:727-32.

83 Drayer JIM, Gardin JM, Weber MA, Aronow WS. Increases and decreases in ventricular septal thickness during diuretic therapy. Clin Pharmacol Ther 1982;32:283-8.

84 Tarazi RC, Sen S, Fouad FM, Wicker R. Regression of myocardial hypertrophy: conditions and sequelae of reversal in hypertensive heart disease. In: Alpert NR, ed. Perspectives in cardiovascular research. Vol 7. Myocardial hypertrophy and failure. New York: Raven, 1983: 637-52.

85 Devereux RB, Savage DD, Sachs I, Laragh JH. Effect of blood pressure control on LV hypertrophy and function in hypertension [abstract]. Circulation 1980;62(suppl II): in hyp.

86 Sen S, Tarazi RC. Regression of myocardial hypertrophy and influence of adrenergic system. Am $\mathcal{f}$ Physiol 1983; 13: H97-101.

87 Garavaglia GR, Messerli FH, Nunez BD, Schmieder RE, Frohlich ED. Angiotensinn converting enzyme inhibitors. Disparities in the mechanism of their antihypertensive effect. Am f Hypertens 1988;1:214-6S.

88 Grandi AM, Venco A Barzizza F, Petrucci E, Scalise F, Perani G, et al. Double-blind comparison of perindopril and captopril in hypertension. Effects on left ventricular morphology and function. Am $\mathcal{f}$ Hypertens 1991; 4:516-20.

89 Schmieder RE, Messerli FH, Sturgill D, Guillermo E, Garavaglia GE, Nunez BD. Cardiac performance after reduction of myocardial hypertrophy. $A m \quad \mathcal{J} M e d$ 1989;87:22-7.

90 Schneeweiss A, Rosenthal J, Marmor A. Comparative evaluation of the acute and chronic effects of cilazapril and hydrochlorothiazide on diastolic cardiac function in hypertensive patients. F Hum Hypertens 1990;4:535-9.

91 Julien J, Dufloux M-A, Prasquier R, Chatellier G, Menard D, Plouin P-F, et al. Effects of captopril and minoxidil on left ventricular hypertrophy in resistant hypertensive patients: a 6 months double-blind comparison. $f A C C$ 1990;16:137-42.

92 Angermann $\mathrm{CE}$, Spes $\mathrm{CH}$, Willems $\mathrm{S}$, Dominiak $\mathrm{P}$, Kemkes BM, Theisen K. Regression of left ventricular hypertrophy in hypertensive heart transplant recipients hypertrophy in hypertensive heart transplant recipients Circulation 1991;84:583-93.

93 Dahlöf $B$, Hansson L. Regression of left ventricular hypertrophy in previously untreated essential hypertension: trophy in previously untreated essential hypertension: different effects of enalapril a

94 Shahi M, Poulter N, Foale RA. The effects of blood pressure reduction on abnormal left ventricular diastolic
function in hypertensive patients. Eur Heart $\mathcal{f} 1991$; 12:974-9. 